\title{
GMR
}

\section{Efficiency of selection per se and in single-cross hybrids for disease resistance in maize}

\author{
R.B. Camargos ${ }^{1}$, R.G. Von Pinho ${ }^{1}$, M. Balestre ${ }^{2}$, R.A.D.C. Ferreira ${ }^{3}$, \\ K.O.G. Dias ${ }^{3}$, L.P.M. Pires ${ }^{1}$ and V.F. Souza ${ }^{1}$ \\ ${ }^{1}$ Departamento de Agricultura, Universidade Federal de Lavras, \\ Lavras, MG, Brasil \\ ${ }^{2}$ Departamento de Ciências Exatas, Universidade Federal de Lavras, \\ Lavras, MG, Brasil \\ ${ }^{3}$ Departamento de Biologia, Universidade Federal de Lavras, \\ Lavras, MG, Brasil \\ Corresponding author: R.G. Von Pinho \\ E-mail: renzovonpinho@gmail.com
}

Genet. Mol. Res. 16 (3): gmr16039716

Received May 9, 2017

Accepted July 3, 2017

Published July 28, 2017

DOI http://dx.doi.org/10.4238/gmr16039716

Copyright $(2017$ The Authors. This is an open-access article distributed under the terms of the Creative Commons Attribution ShareAlike (CC BY-SA) 4.0 License.

\begin{abstract}
Plant breeding strategies are constantly refined to increase efficiency during the selection process. Consequently, the aims of this study were to examine genetic control and efficiency of selection based on the per se performance of maize lines and based on hybrid performance in reaction to white spot, common rust, and ear rot diseases in maize breeding programs. We also aimed to examine the relationship between the per se performance of the lines and the single hybrids for resistance to these diseases. To do so, we evaluated the reaction to these diseases in 106 lines and 661 hybrids in different locations in Brazil. Subsequently, the relative importance of the additive and non-additive genetic effects on expression of these traits, the association between the parameters considered upon carrying out the selection in these generations, and gain from selection were estimated. The results indicated that additive effects predominate for resistance to
\end{abstract}

Genetics and Molecular Research 16 (3): gmr16039716 
white spot and ear rot diseases, whereas for common rust, dominance effects predominate. However, evaluating the hybrids through diallel analysis was effective in selection for resistance to these diseases. The diseases and the generations evaluated were interrelated; the increase in the level of resistance had a more significant correlated response when selection was directed by the reaction to white spot, and there was a greater genetic similarity between the parameters considered in selection directed by hybrid performance.

Key words: Genetic control; Genotype screening; Plant health; Zea mays L.

\section{INTRODUCTION}

Maize (Zea mays L.) is present in practically all states of Brazil and was grown in an area of 15.9 million hectares in Brazil in the 2015/2016 crop season (CONAB, 2017). Because of its wide distribution in soil and climate conditions, this cereal crop has been exposed to multiple pathogens. This has contributed to a situation in which diseases are one of the main impediments to exploiting the genetic grain yield potential in breeding programs for the crop, above all due to losses from leaf and ear rot diseases (Pereira et al., 2015).

Maize white spot (WS), whose etiological agent is the bacteria Pantoea ananatis, is considered one of the main leaf diseases, both because of its geographic distribution and because of its damage potential, and it can cause losses of up to $60 \%$ of grain yield (Carson, 2005). Another important leaf disease, especially in the South-central part of Brazil is common rust (CR), caused by the fungus Puccinia sorghi, which can cause losses of up to $40 \%$ in grain yield (Dey et al., 2015).

In general, these diseases associated with favorable climate conditions and with genotype susceptibility also favor different ear rot diseases (ER) (Brito et al., 2013). Recently, the incidence and severity of these ER diseases have increased in Brazil, especially those caused by the fungi Diplodia maydis and Fusarium verticillioides, which can lead to losses of around $50 \%$ in grain yield due to a considerable reduction in ear weight (Reid et al., 2009). Besides, these diseases hurt grain quality because of the production of mycotoxins, substances that are highly noxious to birds and mammals.

The impact of these pathogens on the maize production chain in Brazil has brought about a broad discussion in breeding programs regarding strategies that can lead to greater efficiency during the process of screening for resistant genotypes. Along with this, questions have often arisen regarding the need to evaluate lines and the efficiency of selection based on hybrid performance, as well as the degree of association between the estimates obtained in these generations.

It should be noted that this depends on the characterization of the germplasm concerning the nature and magnitude of the additive and dominance genetic effects that control reaction to these diseases. Furthermore, linear correlations can be used to infer the degree of association between traits, but they do not allow estimation of the interrelations between the hybrids and their parents concerning several diseases simultaneously.

In this context, the use of diallel analysis in the mixed linear model approach has been recommended for the study of genetic control because it enables more accurate estimates to be obtained compared to the fixed model approach (Ogut et al., 2014). Together with

Genetics and Molecular Research 16 (3): gmr16039716 
that, adoption of the canonical correlation technique is recommended for estimation of the interrelations between two groups of variables composed of several traits; this methodology is still not very evident in the literature on studies of disease resistance and shows potential for effectively contributing to future breeding studies.

Therefore, the aims of this study were to examine genetic control and efficiency of selection based on the per se performance of the lines and based on hybrid performance regarding WS, CR, and ER diseases in maize breeding programs. We also aimed to examine the relationship between the performance in these generations and resistance to these diseases.

\section{MATERIAL AND METHODS}

\section{Conducting and evaluating the experiments}

We used 106 lines from the Germplasm Bank of the Universidade Federal de Lavras that were recently introduced in the maize breeding program of this institution and that had not yet been characterized concerning the level of resistance to diseases. A total of 661 hybrids were synthesized from these genotypes in a system of unbalanced diallel crosses in the 2011/2012 crop season.

In the following crop season, the per se performance of these lines was evaluated in two municipalities in the central region of Brazil, in Lavras, MG, and Uberlândia, MG. Two different experiments were set up at each location, the first inoculated with $F$. verticillioides and the second with D. maydis, according to the procedures for inoculum preparation and inoculation described by Correl et al. (1987), Petatán-Sagahón et al. (2011), and Clements et al. (2003). After that, the reaction to ER, WS, and CR was evaluated in these experiments, which were conducted under natural infection of the etiological agents of the leaf diseases studied.

The lines were randomized in each experiment using an incomplete block design with two interspersed common controls and three replications, and the experimental plots consisted of one 3-m row spacing $0.7 \mathrm{~m}$ between rows.

In the 2012/2013 crop season, from all the hybrids previously generated, 621 were evaluated in four locations distributed in the South of Brazil (Guarapuava-PR, Faxinal dos Guedes-SC, Itapeva-SP, and Ipiranga-PR) and 490 hybrids (including 450 hybrids evaluated in the South of Brazil) were evaluated in five locations in central Brazil (Araguari-MG, Presidente Olegário-MG, Uberaba-MG, Madre de Deus-MG, and Nazareno-MG). These experiments were conducted using a completely randomized block design with three replications per location and plots consisting of four $5-\mathrm{m}$ rows spaced $0.7 \mathrm{~m}$ between rows under natural infection of the etiological agents of WS, CR, and ER.

All the experiments were sown in the no-tillage system in areas in which maize followed by maize had been planted for several crop seasons; planting dates were established according to the sowing times predominant in each region for the summer crop season. Fertilization at planting and in topdressing was carried out according to the technical recommendations for each experimental area, and the crops were treated to control army worm and weed growth, for the maize crop to develop without their interference.

In the experiments conducted with the lines, three methodologies were used to estimate resistance to ER, considering the symptoms of the fungi $D$. maydis and $F$. verticillioides. This consisted of the mean score for damaged kernels in the ears of the plot (SCO), the proportion of ears with symptoms of ear rot (PER), and percentage of damaged kernels (DK\%).

Genetics and Molecular Research 16 (3): gmr16039716 
A diagrammatic scale, with scores from one to seven, was used to evaluate SCO (Reid et al., 2009). For PER, the proportion of ears with ER symptoms was considered concerning the total number of ears of the plot. For $\mathrm{DK} \%$, the procedure proposed by government ordinance No. 11 of April 12, 1996 (Brasil, 1996) was adopted, which establishes a 230-g grain sample per plot for visual separation and determination of the percentage of kernels with discoloring symptoms in more than one-quarter of the total surface area. Furthermore, the severity of the WS and CR leaf diseases was estimated with the aid of the diagrammatic scale proposed by Agroceres (1996) through a single evaluation at 85 days after emergence of the maize plants (Lopes et al., 2011).

In the experiments conducted for evaluation of the hybrids, the reaction to WS, CR, and $\mathrm{DK} \%$ were estimated, according to the procedures presented in the per se performance evaluation of the lines.

The number of genotypes and traits evaluated in each location per region in the per se performance evaluation of the lines and of the hybrids is described in Table 1.

Table 1. Number of genotypes and traits evaluated in each location regarding reaction to white spot (WS), common rust (CR), percentage of damaged kernels (DK\%), the proportion of ears with ear rot symptoms (PER), and mean score for damaged kernels in the ears of the plot (SCO).

\begin{tabular}{|c|c|c|c|c|c|c|c|c|c|c|}
\hline \multirow[t]{2}{*}{ Location } & \multirow[t]{2}{*}{ Code } & \multirow{2}{*}{ Latitude } & \multirow[t]{2}{*}{ Longitude } & Region & Number of genotypes & WS & $\mathrm{CR}$ & DK\% & PER & $\mathrm{SCO}$ \\
\hline & & & & \multicolumn{7}{|l|}{ Per se performance of the lines } \\
\hline Lavras, MG & & $21^{\circ} 14^{\prime} \mathrm{S}$ & $45^{\circ} 00^{\prime} \mathrm{W}$ & Central & 106 & $\mathrm{X}$ & $\mathrm{X}$ & $\mathrm{X}$ & $\mathrm{X}$ & $\mathrm{X}$ \\
\hline \multirow{2}{*}{ Uberlândia, MG } & & $18^{\circ} 55^{\prime} \mathrm{S}$ & $48^{\circ} 16^{\prime} \mathrm{W}$ & Central & 106 & $\mathrm{X}$ & & $\mathrm{X}$ & $\mathrm{X}$ & $\mathrm{X}$ \\
\hline & & & & \multicolumn{7}{|l|}{ Hybrid performance } \\
\hline Araguari, MG & E1 & $18^{\circ} 38^{\prime} \mathrm{S}$ & $48^{\circ} 11^{\prime} \mathrm{W}$ & Central & 367 & & & $\mathrm{X}$ & & \\
\hline Presidente Olegário, MG & E2 & $18^{\circ} 25^{\prime} \mathrm{S}$ & $46^{\circ} 25^{\prime} \mathrm{W}$ & Central & 407 & $\mathrm{X}$ & & $\mathrm{X}$ & & \\
\hline Uberaba, MG & E3 & $19^{\circ} 45^{\prime} \mathrm{S}$ & $47^{\circ} 55^{\prime} \mathrm{W}$ & Central & 367 & $\mathrm{X}$ & & $\mathrm{X}$ & & \\
\hline Madre de Deus, MG & E4 & $21^{\circ} 29^{\prime} \mathrm{S}$ & $44^{\circ} 19^{\prime} \mathrm{W}$ & Central & 397 & $\mathrm{X}$ & & & & \\
\hline Nazareno, MG & E5 & $21^{\circ} 12^{\prime} \mathrm{S}$ & $44^{\circ} 35^{\prime} \mathrm{W}$ & Central & 489 & $\mathrm{X}$ & & & & \\
\hline Guarapuava, PR & E6 & $25^{\circ} 23^{\prime} \mathrm{S}$ & $51^{\circ} 27^{\prime} \mathrm{W}$ & South & 387 & & $\mathrm{X}$ & $\mathrm{X}$ & & \\
\hline Faxinal dos Guedes, SC & E7 & $26^{\circ} 51^{\prime} \mathrm{S}$ & $52^{\circ} 15^{\prime} \mathrm{W}$ & South & 322 & & $\mathrm{X}$ & $\mathrm{X}$ & & \\
\hline Itapeva, SP & E8 & $23^{\circ} 58^{\prime} \mathrm{S}$ & $48^{\circ} 52^{\prime} \mathrm{W}$ & South & 448 & & $\mathrm{X}$ & $\mathrm{X}$ & & \\
\hline Ipiranga, PR & E9 & $25^{\circ} 01^{\prime} \mathrm{S}$ & $50^{\circ} 35^{\prime} \mathrm{W}$ & South & 387 & & $X$ & $X$ & & \\
\hline
\end{tabular}

\section{Estimation of per se performance and of combining ability of the lines}

Based on the traits presented and on the experimental design used in the evaluation of the per se performance of the lines, statistical analyses were carried out using the following mixed linear model of Equation 1:

$$
\mathbf{y}=\boldsymbol{\mu} 1+\mathbf{X} \boldsymbol{\beta}+\mathbf{Z}_{1} \mathbf{a}+\mathbf{Z}_{2} \mathbf{b}+\mathbf{Z}_{3} \boldsymbol{\alpha}+\mathbf{Z}_{4} \mathbf{l x a}+\mathbf{Z}_{5} \mathbf{l x f} \mathbf{x a}+\varepsilon \quad \text { (Equation 1) }
$$

where $\mathbf{y}$ is the observed value of the plot for each trait; $\mu 1$ is the constant; is the vector of fixed effects of inoculum, locations, replication within fungi within locations, and fungus $\mathrm{x}$ environment interaction; $\mathbf{a}$ is the vector of random effects of lines; $\mathbf{b}$ is the vector of random block effects within replication, within fungi, and within locations; $\alpha$ is the vector of random effects of the line $\mathrm{x}$ fungus interaction; lxa is the vector of random effects of the line $\mathrm{x}$ environment interaction; lxfxa is the vector of random effects of the line $\mathrm{x}$ fungus $\mathrm{x}$ environment interaction; and $\varepsilon$ is the vector of experimental error. $\mathbf{X}, \mathbf{Z}_{1}, \mathbf{Z}_{2}, \mathbf{Z}_{3}, \mathbf{Z}_{4}$, and $\mathbf{Z}_{5}$ represent the incidence matrices for the respective effects. 
Given this model, genetic variance, mean heritability, and accuracy were estimated for the traits considered in these experiments, as well as the standard error associated with the estimates of genetic variance and heritability through the delta method (Kendall and Stuart, 1963) using the nadiv package (Wolak, 2012) available in the R software (R Core Team, 2015).

To estimate the relative importance of the additive and non-additive genetic effects on expression of the characteristics evaluated, the method four of diallel analysis proposed by Griffing (1956) was adopted, using only the hybrid combinations. This methodology allowed a breakdown of the genotype effect (diallel hybrids) into general combining ability (GCA) and specific combining ability (SCA) effects.

For that purpose, the estimates of the BLUPs of the GCA and the SCA were obtained through the mixed linear model presented in Equation 2:

$$
\mathbf{y}=\boldsymbol{\mu} 1+\mathbf{X} \boldsymbol{\beta}+\mathbf{Z}_{1} \mathbf{g}+\mathbf{Z}_{2} \mathbf{s}+\mathbf{Z}_{3} \mathbf{g x a}+\mathbf{Z}_{4} \mathbf{s x a}+\mathcal{E} \quad \text { (Equation 2) }
$$

where $\mathbf{y}$ is the vector of the phenotypic observations; $\mu 1$ is the constant; is the vector of fixed effects of environment, experiment within environments, replications within experiment, and within environments; $\mathbf{g}$ is the vector of random effects of the GCA; $\mathbf{s}$ is the vector of random effects of the SCA; gxa is the vector of random effects of the interaction between GCA and environments; sxa is the vector of random effects of the interaction between SCA and environments; and is the vector of the random effects of residues. $\mathbf{X}, \mathbf{Z}_{1}, \mathbf{Z}_{2}, \mathbf{Z}_{3}$, and $\mathbf{Z}_{4}$ represent the incidence matrices for the respective effects.

With the above model and the traits considered in mind, we estimated the variance of the GCA and the SCA, mean heritability, and accuracy. We also estimated the standard error associated with estimates of the components of variance through the delta method (Kendall and Stuart, 1963) using the nadiv package, available in the R software (R Core Team, 2015).

To better visualize the interaction of the GCA and the SCA across the environments evaluated, the GGE biplot graphic was plotted (genotype and genotype by environment interaction), proposed by Yan et al. (2009), considering the 10 best and 10 worst genotypes regarding each one of the traits studied.

Analyses were carried out using the mixed model approach, in which the BLUPs of the lines of the GCA, and the SCA were obtained with the aid of the SAS 8.0 software (SAS Institute, 2000). This software was also used to carry out GGE biplot analysis with IML (interactive matrix language) and SAS GRAPH to generate the GGE biplot graphs.

\section{Relationship between hybrid performance and per se performance of the lines}

In the selection strategy directed by hybrid performance, the additive value of the lines is predicted by the GCA, and to evaluate the efficiency of this methodology, the BLUPs of the GCA were compared with the BLUPs of the per se performance of the lines. In contrast, in the selection strategy based on per se performance of the lines, the genotypic value of the hybrids is predicted by the per se performance of the lines. Consequently, to estimate its efficiency, the BLUPs of the per se performance of the lines were compared to the product of the sum of the BLUPs of the GCA and the mean SCA for each parent.

The association between the estimates of the parameters considered in these selection strategies was made by estimation of the Spearman rank correlation, creation of correlation

Genetics and Molecular Research 16 (3): gmr16039716 
graphs considering the 20 best genotypes regarding reaction to the diseases evaluated, and estimation of the index of coincidence, which was obtained by the ratio of correlation between the estimates of these parameters from analysis of the graphs. Besides, gain from selection was estimated, considering the 20 best genotypes.

\section{Canonical correlations}

The multivariate technique of the canonical correlations was used to describe the maximum correlation between the groups of canonical variables considered in selection based on hybrid performance and on per se performance of the lines, which were composed of linear combinations of the three diseases evaluated. This allowed the interrelations between these traits in each one of these generations to be estimated, according to the procedures described by Cruz et al. (2012).

Euclidean distances were used to perform a study on genetic divergence considering the traits and the parameters evaluated in these selection strategies to study the degree of genetic similarity among the complexes of variables analyzed. To facilitate visualization of the association between the parameters considered in each strategy, the distance matrix was projected on a three-dimensional graph, and the canonical correlations and the study of genetic divergences by canonical variables were carried out the Genes software (Cruz, 2013).

\section{RESULTS AND DISCUSSION}

\section{Estimation of the per se performance and the combining ability of the lines}

The experimental precision obtained in the evaluation of the per se performance of the lines indicated by the accuracy values for WS, CR, SCO, and DK\% was low to moderate, but for PER it was of high magnitude (Table 2) (Resende and Duarte, 2007). Although accuracy was not high for all the traits analyzed, it was sufficient to detect variation among the lines for all the traits, just as found in this case by the significance of the genetic variance among these genotypes. The genotype $\mathrm{x}$ environment interaction was significant for these traits, and this was favored by the climate differences between Lavras, MG, with highland tropical climate, and Uberlândia, MG, with tropical climate with a dry season. Similarly, Pereira et al. (2015) reported a significant genotype $\mathrm{x}$ environment interaction regarding reaction to leaf and ER diseases in experiments conducted for evaluation of maize lines in these locations.

Table 2. Estimate of genetic variance $\left(\sigma_{\mathrm{g}}^{2}\right)$, heritability $\left(\mathrm{h}^{2}\right)$, and accuracy $\left(r_{\mathrm{gg}}^{2}\right)$ from evaluation of per se performance of the maize lines regarding the traits white spot (WS), common rust (CR), the proportion of ears with ear rot (PER), score given to ears for severity of damaged kernels (SCO), and percentage of damaged kernels (DK\%).

\begin{tabular}{l|c|c|c|c|c}
\hline Parameter & WS & CR & PER & SCO & DK\% \\
\hline$\sigma^{2}$ & $0.34^{* *}$ & $0.18^{*}$ & $0.03^{*}$ & $0.04^{*}$ & $18.56^{* *}$ \\
$(\mathrm{SE})$ & $( \pm 0.27)$ & $( \pm 0.02)$ & $( \pm 0.01)$ & $( \pm 0.14)$ & $( \pm 7.89)$ \\
\hline$h^{2}(\%)$ & 15.01 & 20.32 & 65.01 & 4.75 & $( \pm 0.08)$ \\
$(\mathrm{SE})$ & $( \pm 0.09)$ & $( \pm 0.13)$ & $( \pm 0.17)$ & 21.79 & $( \pm 0.12)$ \\
\hline$r_{\mathrm{gg}}^{2}(\%)$ & 38.74 & 45.07 & 80.63 & 51.87 \\
\hline
\end{tabular}

$\mathrm{SE}=$ standard error; $* * *$ significant at 5 and $1 \%$ probability, respectively, by the likelihood ratio test (LRT).

The GCA and the SCA that are related to the frequency of favorable alleles in the parents and to the gene complementation that is expressed as heterosis due to the effects of the

Genetics and Molecular Research 16 (3): gmr16039716 
deviations of dominance and epistasis in the hybrid combinations, respectively, were significant for $\mathrm{CR}$ and $\mathrm{DK} \%$, showing that the additive and non-additive effects were important in genetic control of these diseases, just as reported by Kulbir et al. (2006) and Hung and Holland (2012). In the case of WS, only the GCA was significant (Table 3), indicating a little contribution from SCA; a study conducted by Lopes et al. (2007) obtained a similar result.

Table 3. Estimates of variance of general combining ability $\left(\sigma_{G C A}^{2}\right)$, variance of specific combining ability $\left(\sigma_{S C A}^{2}\right)$, heritability $\left(\mathrm{h}^{2}\right)$, and accuracy $\left(r^{2} g\right.$ ) obtained from evaluation of the maize hybrids regarding white spot (WS), common rust (CR), and percentage of damaged kernels (DK\%).

\begin{tabular}{l|c|c|c}
\hline Parameter & WS & CR & DK\% \\
\hline$\sigma_{G C A}^{2}$ & $0.19^{* *}$ & $0.05^{*}$ & $0.38^{* *}$ \\
$(\mathrm{SE})$ & $( \pm 0.04)$ & $( \pm 0.02)$ & \\
\hline$\sigma_{S C A}^{2}$ & $3.44 \times 10^{-6 \mathrm{NS}}$ & $0.06^{* *}$ & $0.05^{*}$ \\
$(\mathrm{SE})$ & $\left( \pm 1.44 \times 10^{-6}\right)$ & $( \pm 0.05)$ & $( \pm 0.01)$ \\
\hline$h^{2}(\%)$ & & & 37.40 \\
$(\mathrm{SE})$ & $( \pm 1.94 .82)$ & $( \pm 12.25)$ & $( \pm 0.09)$ \\
\hline$r_{g g}^{2}(\%)$ & 56.52 & 52.46 & 61.15 \\
\hline
\end{tabular}

$\mathrm{SE}=$ standard error. ${ }^{\mathrm{NS}},{ }^{*},{ }^{*}$ Nonsignificant, and significant at 5 and $1 \%$ probability, respectively, by the LRT test.

Considering the traits studied in evaluation of per se performance of the lines and hybrid performance, higher values were found for the accuracy estimates in the results coming from evaluation of the hybrids, indicating better experimental precision in conducting these experiments in relation to those with the lines (Tables 2 and 3) (Resende and Duarte, 2007).

The estimates of heritability presented in Tables 2 and 3 show the possibility of success in selection in the two generations studied for the three diseases. However, from reports in the literature, more significant heritability values would be expected, in the order of $40-80 \%$ for these diseases (Robertson-Hoyt et al., 2006; Lopes et al., 2007; Wanlayaporn et al., 2013). This was observed only for PER, which corresponds to an evaluation method that has less subjectivity since it considers only the incidence of the pathogen and not its severity, as in the other traits studied, which provided greater experimental precision (Pereira et al., 2015).

Considering that the genotype $\mathrm{x}$ environment interaction was significant for the characteristics considered in evaluation of the per se performance of the lines and the hybrids, there was an increase in the phenotypic standard deviation and, as a result of that, a reduction in the estimates of accuracy and heritability (Matheson and Raymond, 1986). This explains the lower estimates obtained for these parameters in this study, above all in the per se evaluation, because high homozygosity reduces the expression of traits that contribute to better adaptation to environmental changes, resulting in plants that are more sensitive to environmental variations than the hybrids that are highly heterozygous. Li et al. (2014) obtained similar results in a study conducted to evaluate the performance of maize lines and their respective hybrids in five locations in China.

In an analysis of the GCA x environment interaction (Figure 1), a significant difference was found in the GCA performance among the environments evaluated; consequently, the expression of the favorable alleles donated by the parents varied among these environments. This corroborates the results obtained by Vivek et al. (2010), who detected significant GCA x environment interaction upon conducting diallel analysis considering seven maize diseases, including those evaluated in this study.

Genetics and Molecular Research 16 (3): gmr16039716 

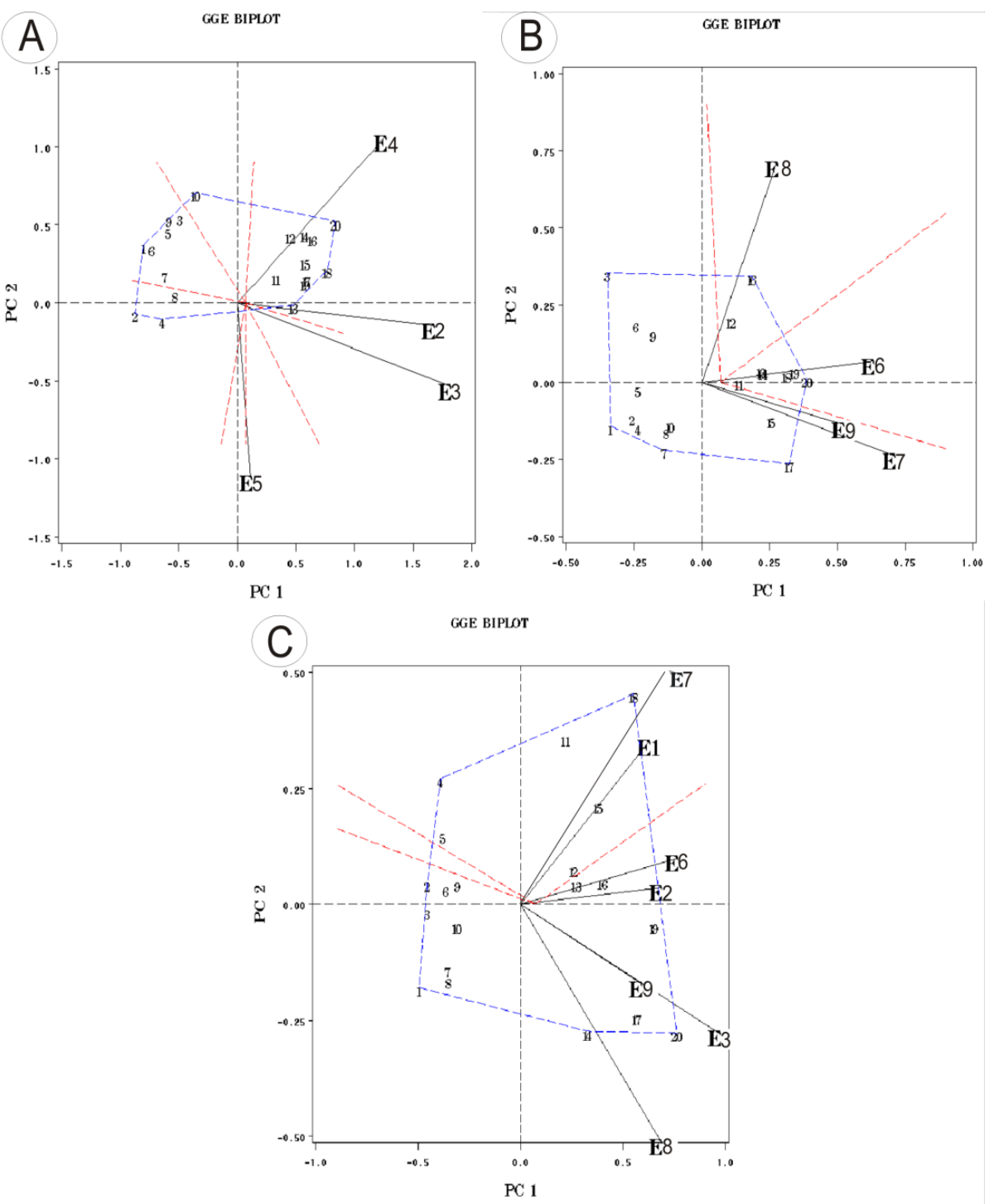

Figure 1. GGE biplots with the first two principal components, GCA + GCA x environments, corresponding to the representation of the 10 maize lines most and least resistant to white spot $(\mathbf{A})$, common rust (B), and percentage of damaged kernels $(\mathbf{C})$. E\# corresponds to environments, with each line being identified by its respective cardinal number due to its position in the ranking, 1-10 most resistant, and 11-20 most susceptible.

In a similar manner, a significant difference was found in the performance of the SCA among the environments studied, showing that the expression of gene complementation between the parents varied across the environments evaluated (Figure 2), just as Lopes et al. (2007), Jha (1993), and Hung and Holland (2012) detected from data from evaluation of WS, $\mathrm{CR}$, and ER, respectively.

Genetics and Molecular Research 16 (3): gmr16039716 

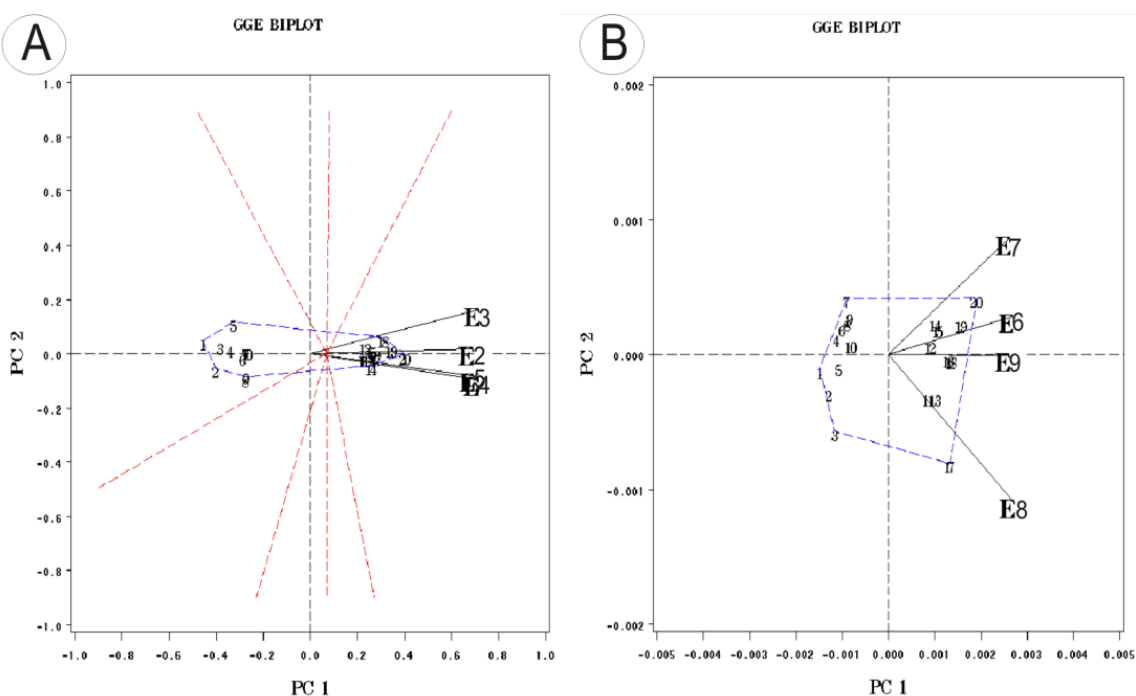

GGE BIPLOT

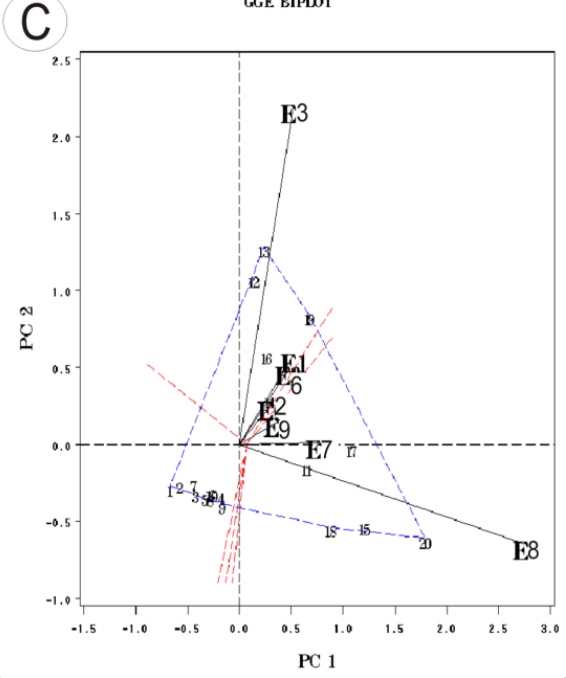

Figure 2. GGE biplots with the first two principal components, SCA + SCA x environments, corresponding to the representation of the 10 maize hybrids most and least resistant to white spot (A), common rust $(\mathbf{B})$, and percentage of damaged kernels (C). E\# corresponds to environments, with each hybrid being identified by its respective cardinal number due to its position in the ranking, 1-10 most resistant, and 11-20 most susceptible.

Considering that in the GGE biplot exploratory analysis, the first and the second principal component refer to the adaptability and stability of the genotypes, the results in Figures 1 and 2 show genotypes with performance specific to some environments and the possibility of environmental stratification from these genetic parameters. This reinforces the need for diallel analysis and the study of the genotype $\mathrm{x}$ environment interaction to allow selection and more precise placement of genotypes that are superior regarding WS, CR, and ER in each region.

Genetics and Molecular Research 16 (3): gmr16039716 
Analysis of the estimates of a variance of GCA and SCA and the degree of dominance obtained by the ratio between these parameters (SCA/GCA) showed that additive effects predominated in the genetic control of the reaction to WS and ER, whereas dominance effects predominated in genetic control of the reaction to CR (Table 3 ).

The results of studies conducted by Carson (2005) and Sibiya et al. (2011), who evaluated maize genotypes in the USA and South Africa, corroborate the results obtained regarding the predominantly additive degree of dominance found in this study for reaction to WS.

CR can exhibit a predominance of additive or dominance effects, and in this study, the degree of dominance obtained is in agreement with that presented by Jha (1993), who found a predominance of dominance effects in analyzing the results of experiments conducted under inoculation of the fungus that causes this disease.

In this case, a significant contribution from GCA, as presented in Table 3, would not be expected; but this may be explained from the experiments having been conducted across a wide geographic region under natural infection from the etiological agent of this disease. This favors the rise of various races of the pathogen, which may lead to what is known as the Parlevliet effect, in which there is a false appearance of significant contribution from GCA, that is, of quantitative resistance, observed when the population of the host and the pathogen is heterogeneous (Sidhu, 1984).

In reaction to damaged kernels caused by $F$. verticillioides and $D$. maydis, the predominance of additive effects corroborates the results previously obtained by Vivek et al. (2010), Hung and Holland (2012), and Rossouw et al. (2002).

\section{Relationship between hybrid performance and per se performance of the lines}

In analyzing the efficiency of selection directed by hybrid performance (Table 4) and per se performance of the lines (Table 5), it can be observed that for the WS, the correlation between the parameters estimated in both selection strategies was positive, moderate, and significant. Associated with this, a high index of coincidence was found between the parameters considered in these methodologies, as presented in the graphs of Figures 3 and 4. Further corroboration was found in gain from selection in both cases (Tables 6 and 7), above all when the selection was made based on hybrid performance.

Table 4. Estimates of Spearman rank correlation among the parameters considered in selection directed by hybrid performance regarding resistance to white spot (WS), common rust (CR), the proportion of ears with ear rot (PER), score given to ears for severity of damaged kernels (SCO), and percentage of damaged kernels (DK\%).

\begin{tabular}{l|c|c|c|c|c}
\hline Trait selected & \multicolumn{5}{|c}{ BLUPs of per se performance of the lines } \\
\hline BLUPs of the GCA & WS & CR & PER & SCO & DK\% \\
\hline WS & $0.63^{* *}$ & & & & \\
\hline CR & & $-0.19^{*}$ & & & \\
\hline DK $\%$ & & & $0.17^{*}$ & $0.18^{*}$ & $-0.02^{\mathrm{NS}}$ \\
\hline
\end{tabular}

Ns $* * *$ Nonsignificant, and significant at 5 and $1 \%$ probability, respectively, by the $t$-test. GCA $=$ general combining ability.

For ER, the correlation between the parameters considered in selection directed by hybrid performance (Table 4) and per se performance of the lines (Table 5) exhibited estimates of positive, low, and significant correlation for PER and SCO, as well as a negative, low, and non-significant correlation for $\mathrm{DK} \%$. Although correlations of low magnitude were obtained, there was a high index of coincidence between the parameters analyzed regarding PER and

Genetics and Molecular Research 16 (3): gmr16039716 
SCO in both selection strategies and moderate coincidence between the parameters considered for the DK\% trait (Figures 3 and 4). In this case, the estimates showed that there is gain from selection in both cases (Tables 6 and 7), and it is most significant when the selection is directed by evaluation of the hybrids and by the traits PER and SCO.

Table 5. Estimates of Spearman rank correlation for the parameters considered in selection directed by per se performance of the lines regarding resistance to white spot (WS), common rust (CR), the proportion of ears with ear rot (PER), score given to ears for severity of damaged kernels (SCO), and percentage of damaged kernels (DK\%).

\begin{tabular}{l|c|c|c}
\hline Trait selected & \multicolumn{3}{|c}{ BLUPs of the GCA+SCA } \\
\hline BLUPs of per se performance of the lines & WS & CR & DK\% \\
\hline WS & $0.62^{* *}$ & $-0.02^{\mathrm{NS}}$ & \\
\hline CR & & & $0.18^{*}$ \\
\hline PER & & & $0.19^{*}$ \\
\hline SCO & & & $-0.03^{\mathrm{NS}}$ \\
\hline DK $\%$ & & & \\
\hline
\end{tabular}

NS $* * *$ Nonsignificant, and significant at 5 and $1 \%$ probability, respectively, by the $t$-test. GCA $=$ general combining ability; SCA = specific combining ability.

Table 6. Estimates of gain from selection directed by hybrid performance regarding resistance to white spot (WS), common rust (CR), the proportion of ears with ear rot (PER), score given to ears for severity of damaged kernels (SCO), and percentage of damaged kernels (DK\%).

\begin{tabular}{l|c|c|c|c|c}
\hline \multirow{2}{*}{ Trait selected } & \multicolumn{5}{|c}{ Gain from selection (\%) } \\
\cline { 2 - 6 } & \multicolumn{5}{|c}{ BLUPs of per se performance of the lines } \\
\hline BLUPs of the GCA & WS & CR & PER & SCO & DK\% \\
\hline WS & -6.19 & & & & \\
\hline CR & & 5.44 & -19.70 & -4.75 & -1.35 \\
\hline DK\% & & & & \\
\hline
\end{tabular}

GCA = general combining ability.

Table 7. Estimates of gain from selection directed by per se performance of the lines regarding resistance to white spot (WS), common rust (CR), the proportion of ears with ear rot (PER), score given to ears for severity of damaged kernels (SCO), and percentage of damaged kernels (DK\%).

\begin{tabular}{l|c|c|c}
\multirow{2}{*}{ Traits selected } & \multicolumn{3}{|c}{ Gain from selection (\%) } \\
\cline { 2 - 4 } & \multicolumn{3}{|c}{ BLUPs of GCA+SCA } \\
\hline BLUPs of per se performance of the lines & WS CR & DK\% \\
\hline WS & -1.64 & 0.21 & -5.36 \\
\hline CR & & & -0.84 \\
\hline PER & & & -0.81 \\
\hline SCO & & & \\
\hline
\end{tabular}

GCA = general combining ability; SCA = specific combining ability.

These results show that the reaction to WS and ER in the hybrids and the lines was interrelated, as described by Hung and Holland (2012) and Menkir and Ayodele (2005), who conducted their studies evaluating maize pathosystem-damaged kernels and leaf diseases, respectively. The association between these generations is explained by the predominance of additive effects in control of resistance to these diseases.

Considering that gain from selection was of greater magnitude when screening of genotypes was conducted based on hybrid performance (Tables 6 and 7), and since this strategy may allow estimation of the combining ability of the lines, it is ideal for evaluation of reaction to WS and ER in breeding programs. Thus, it is possible to select lines with greater frequency

Genetics and Molecular Research 16 (3): gmr16039716 
of favorable alleles (Balestre et al., 2008) and utilize dominance effects that are not exploited in the evaluation of the lines and, consequently, predict the best crosses.

Furthermore, concentrating efforts in the diallel analysis, it is possible to perform a broader study of adaptability and stability during the studies of genotype selection and simultaneously identify parents that upon being used in crosses express not only resistance to these diseases, but also characteristics of agronomic interest (Menkir and Ayodele, 2005).

In the study of the degree of association between the parameters considered in selection directed by hybrid performance (Table 4) and per se performance of the lines (Table 5) for CR, estimates of negative correlation of low magnitude were obtained in both strategies and they were significant only when selection was directed by hybrid performance.

In this respect, the little coincidence was found between the parameters considered in these selection strategies (Figures 3 and 4). Corroborating these results, gain from selection was not observed in the sense of reducing the severity of this disease with the use of these methodologies. This showed that these selection strategies were not efficient for identification of superior genotypes with respect to this disease.

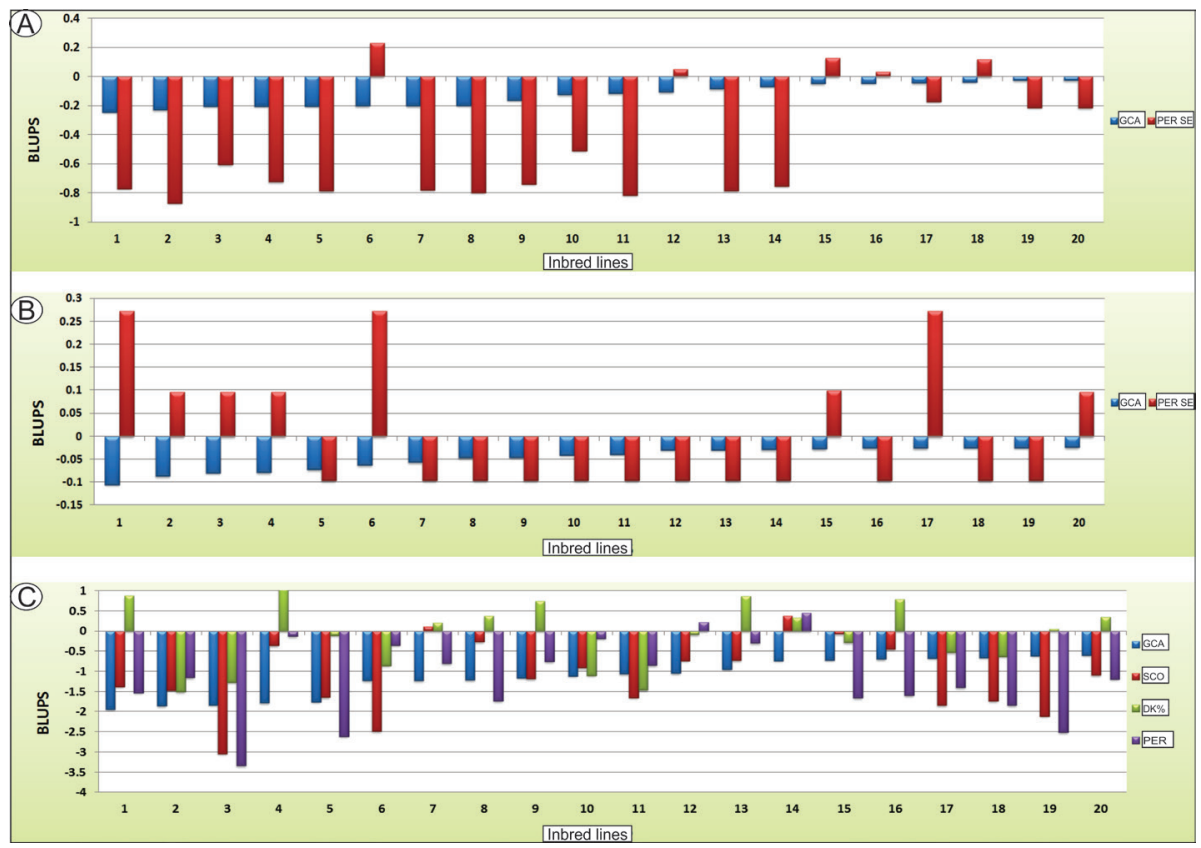

Figure 3. Graphs of correlation between the parameters considered in selection directed by hybrid performance regarding resistance to white spot $(\mathbf{A})$, common rust $(\mathbf{B})$, and the following traits related to damaged kernels $(\mathbf{C})$ : the proportion of ears with ear rot (PER), score given to ears for severity of damaged kernels (SCO), and percentage of damaged kernels (DK\%). The 20 most resistant maize lines are considered, each one of them identified by its respective cardinal number, according to ranking. Per se and GCA correspond to the BLUPs of per se performance of the lines and the general combining ability, respectively.

These results indicate that the use of hybrid evaluation is also recommended for this disease, and that during diallel analysis, focus should be given to SCA because the results mentioned above and observation of the predominance of dominance effects show that expression of this characteristic is dependent on genetic divergence and frequency of

Genetics and Molecular Research 16 (3): gmr16039716 
resistance alleles between the parents (Falconer and Mackay, 1990). Wisser et al. (2006) emphasize this upon describing several dominant alleles involved in the control of qualitative resistance to this disease. Besides, new specificities of genetic resistance are generated during the crosses through gene recombination (Richter et al., 1995), making performance evaluation of the descendants of the crosses fundamental for success during the selection process.

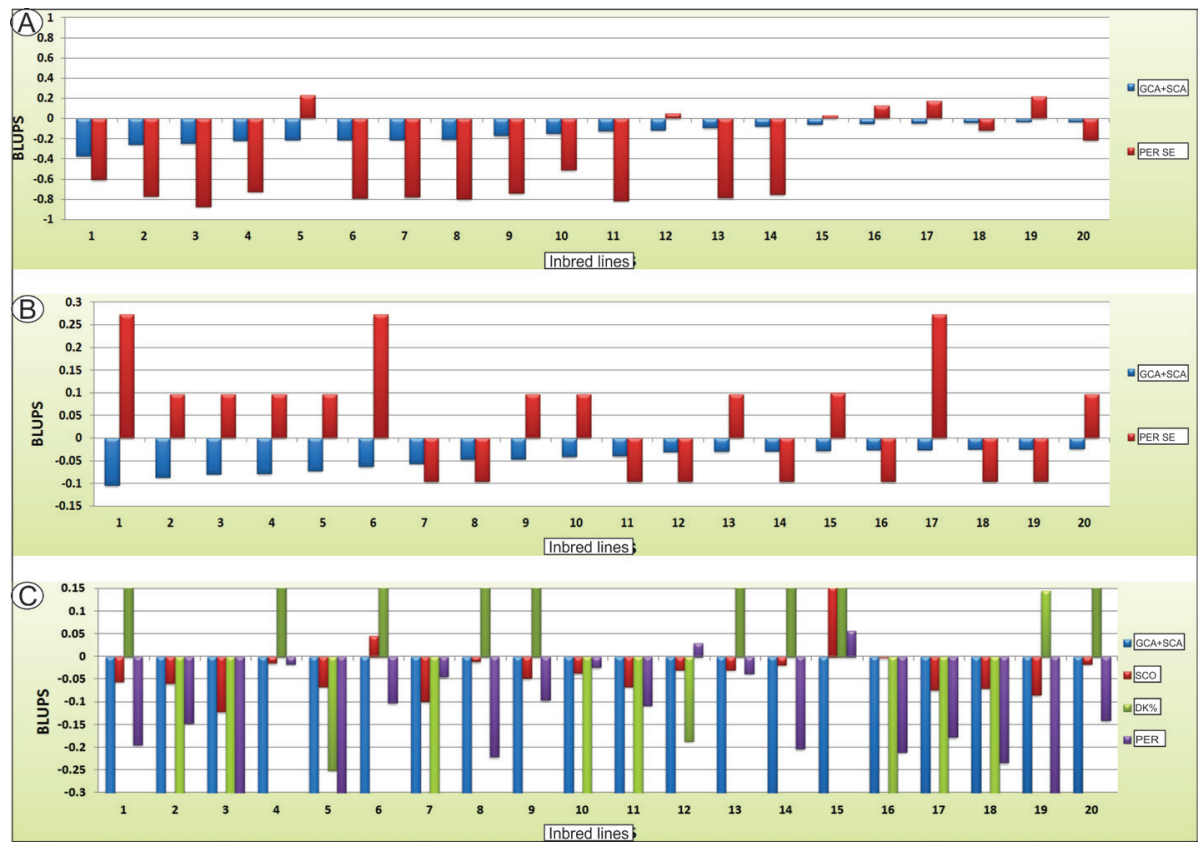

Figure 4. Graphs of correlation between the parameters considered in selection directed by per se performance of the lines regarding resistance to white spot $(\mathbf{A})$, common rust $(\mathbf{B})$, and the following traits related to damaged kernels (C): the proportion of ears with ear rot (PER), score given to ears for severity of damaged kernels (SCO), and percentage of damaged kernels (DK\%). The 20 most resistant maize genotypes are considered, each one of them identified by its respective cardinal number, according to ranking. Per se, GCA, and SCA correspond to the BLUPs of per se performance of the lines, general combining ability, and specific combining ability, respectively.

\section{Canonical correlations}

Simultaneously considering the three diseases evaluated and the parameters considered in selection directed by hybrid performance and by per se performance of the lines, multicollinearity was significant for the traits $\mathrm{SCO}$ and DK\%, impeding the use of these traits in multivariate canonical correlation analysis as described by Cruz and Carneiro (2003).

The first canonical pair, the only significant one among those studied in both selection strategies, had moderate and a significant correlation at the level of $1 \%$ probability by the chi-square test. This confirms the expectation that the parameters considered in these methodologies, as well as the mechanisms of resistance to these diseases, are interrelated, as observed by Arnhold (2008) in evaluating ER and WS, among other diseases. Thus, it was found that simultaneous selection for these diseases has satisfactory results in increasing the level of resistance to these diseases, which indicates the possibility of pyramiding alleles for development of genotypes with multiple resistances.

Genetics and Molecular Research 16 (3): gmr16039716 
Since canonical loadings measure the simple linear correlation between an original variable observed in the groups and the canonical statistical variable of its respective group, the greater the loading, the more important the variable is for deriving the canonical statistical variable (Hair Jr et al., 2009). Thus, the correlation of the first canonical pair, which associates the parameters considered in selection directed by hybrid performance and by per se performance of the lines, indicated that the canonical loading corresponding to the level of resistance to WS determined an increase in the level of resistance to this disease and the others considered in these selection strategies. Therefore, the WS had high canonical loading, resulting in high shared variance, greater than $90 \%$ in both strategies.

For more information regarding efficiency of selection based on hybrid performance and per se performance of the lines, the study of genetic divergence through estimation of the scatter plot of the matrix of Euclidean distances for the variables analyzed (Figure 5) confirmed that the parameters used in selection directed by hybrid performance have greater genetic similarity (Cruz et al., 2012). Consequently, this is the most significant strategy for incorporation in the selection process, which is highly relevant for directing future breeding studies. Although there is a predominance of additive effects for WS and ER, these results show that the contribution of SCA has a significant impact on the degree of genetic similarity of these genotypes, above all for ER, in which the SCA was significant, and for CR, in which dominance effects predominate. Thus, since this parameter is not predicted in selection directed by per se performance of the lines, selection in this generation becomes less efficient.

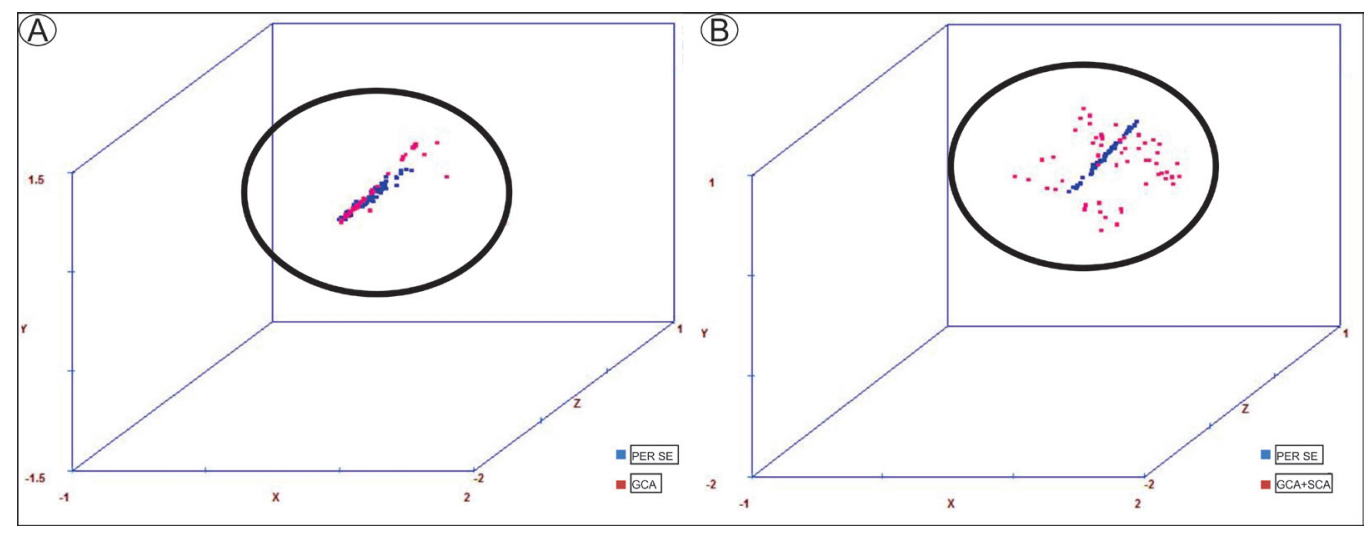

Figure 5. Scatter plot in three-dimensional space of the Euclidean distances, created with the estimates of the parameters considered in reaction to white spot, common rust, and ear rot diseases. A. Parameters considered in selection based on hybrid performance. B. Parameters considered in selection based on per se performance of the lines. Per se, GCA, and SCA correspond to the BLUPs of per se performance of the lines, general combining ability, and specific combining ability, respectively.

In this study, the use of mixed models associated with univariate and multivariate techniques made it possible to describe the relationship between the parameters considered in selection directed by hybrid performance and per se performance of the lines for WS, CR, and ER. Upon carrying out this study with the use of canonical correlations (multivariate approach), simplification in the set of variables analyzed was possible, providing information concerning the correlated response in the selection process simultaneously involving these

Genetics and Molecular Research 16 (3): gmr16039716 
three diseases in the generations evaluated. Nevertheless, replication of this study with other germplasms and environments is recommended to clarify and expand understanding of the degree of association between the diseases and the parameters considered in these selection strategies, above all because in the literature examined, we did not find studies using the canonical correlations in this context.

\section{CONCLUSIONS}

In the germplasm studied, additive effects predominate for resistance to white spot and ear rot diseases, whereas dominance effects predominate for common rust.

However, only evaluation of the hybrids through diallel analysis is more efficient for selection concerning the level of resistance to these diseases in a breeding program.

The diseases and the generations evaluated are interrelated; the increase in the level of resistance has a more significant correlated response when selection is directed by the reaction to white spot, and there is greater genetic similarity among the parameters considered in selection directed by hybrid performance.

\section{ACKNOWLEDGMENTS}

We thank Coordenação de Aperfeiçoamento de Pessoal de Nível Superior (CAPES) for financial support.

\section{REFERENCES}

Agroceres (1996). Guia Agroceres de Sanidade. Sementes Agroceres, São Paulo.

Arnhold E (2008). Seleção para resistência a doenças foliares em famílias S1 de milho-pipoca. Rev. Ceres 2: 89-93.

Balestre M, Machado JC, Lima JL, Souza JC, et al. (2008). Genetic distance estimates among single cross hybrids and correlation with specific combining ability and yield in corn double cross hybrids. Genet. Mol. Res. 7: 65-73. https:// doi.org/10.4238/vol7-1gmr403

Brasil (1996). Portaria ${ }^{\circ}$ 11, de 12 de abril de 1996 estabelece critérios complementares para classificação do milho. Diário Oficial da União.

Brito AH, Von Pinho RG, Pereira JLAR and Balestre M (2013). Controle químico da cercosporiose, mancha-branca e dos grãos ardidos em milho. Rev. Ceres 5: 629-635. https://doi.org/10.1590/S0034-737X2013000500005

Carson ML (2005). Yield loss potential of Phaeosphaeria leaf spot of maize caused by Phaeosphaeria maydis in the United States. Plant Dis. 89: 986-988. https://doi.org/10.1094/PD-89-0986

Clements MJ, Kleinschmidt CE, Maragos CM and Pataky JK (2003). Evaluation of inoculation techniques for fusarium ear rot and fumonisin contamination of corn. Plant Dis. 87: 147-153. https://doi.org/10.1094/PDIS.2003.87.2.147

CONAB (2017). Séries Históricas. Companhia Nacional de Abastecimento. Available at [http://www.conab.gov.br/ conteudos.php?a=1252\&Pagina_objcmsconteudos=3\#A_objcmsconteudos]. Accessed June 2017.

Correl JC, Klittich CJR and Leslie JF (1987). Nitrate nonutilizing mutants of Fusarium oxysporum and their use in vegetative compatibility tests. Phytopathology 77: 1640-1646. https://doi.org/10.1094/Phyto-77-1640

Cruz CD (2013). GENES a software package for analysis in experimental statistics and quantitative genetics. Acta Scientiarum 3: 271-276.

Cruz CD and Carneiro PCS (2003). Modelos biométricos aplicados ao melhoramento genético. Universidade Federal de Viçosa, Viçosa.

Cruz CD, Regazzi AJ and Carneiro PCS (2012). Modelos biométricos aplicados ao melhoramento genético. Universidade Federal de Viçosa, Viçosa.

Dey U, Harlapur SI, Dhutraj DN, Suryawanshi AP, et al. (2015). Integrated disease management strategy of common rust of maize incited by Puccinia sorghi Schw. Afr. J. Microbiol. Res. 20: 1345-1351.

Falconer DS and Mackay TF (1990). Introduction to quantitative genetics. 4th edn. Longman, Essex.

Genetics and Molecular Research 16 (3): gmr16039716 
Griffing B (1956). A generalized treatment of the use of diallel crosses in quantitative inheritance. Heredity 10: 31-50. https://doi.org/10.1038/hdy.1956.2

Hair Jr JF, Black WC, Babin BJ, Anderson RE, et al. (2009). Análise multivariada de dados. Bookman, Porto Alegre.

Hung HY and Holland JB (2012). Diallel analysis of resistance to Fusarium ear rot and fumonisin contamination in maize. Crop Sci. 52: 2173-2181. https://doi.org/10.2135/cropsci2012.03.0154

Jha PB (1993). Diallel analysis for resistance to common rust and turcicum leaf blight in maize. Proc. Nat. Acad. Sci. India 63: 237-241.

Kendall M and Stuart A (1963). The advanced theory of statistics. Griffin, London.

Kulbir S, Gill GK, Satija DR and Bhat MA (2006). Combining ability for resistance to common rust (Puccinia sorghi) in maize (Zea mays L.). Crop Improv. 33: 144-150.

Li Y, et al. (2014). Contributions of parental inbreds and heterosis to morphology and yield of single-cross maize hybrids in China. Crop Sci. 54: 76-88. https://doi.org/10.2135/cropsci2013.02.0077

Lopes MTG, Lopes R, Brunelli KR, Silva HP, et al. (2007). Controle genético da resistência à mancha-de-Phaeosphaeria em milho. Cienc. Rural 37: 605-611. https://doi.org/10.1590/S0103-84782007000300001

Lopes MTG, Vieira MLC and Lopes R (2011). Progeny evaluation for resistance to Phaeosphaeria leaf spot in tropical maize. Can. J. Plant Pathol. 33: 49-53. https://doi.org/10.1080/07060661.2010.534895

Matheson AC and Raymond CA (1986). A review of provenance x environment interaction. Its practical importance and use with particular reference to the tropics. Commonw. Forest. Rev. 65: 283-302.

Menkir A and Ayodele M (2005). Genetic analysis of resistance to Grey Leaf spot of midaltitude maize inbred lines. Crop Sci. 45: 163-170. https://doi.org/10.2135/cropsci2005.0803

Ogut F, Maltecca C, Whetten R, McKeand, et al. (2014). Genetic analysis of diallel progeny test data using factor analytic linear mixed models. Gen Tree Improv. 60: 119-127.

Pereira GS, Camargos RB, Balestre M, Von Pinho RG, et al. (2015). Indirect selection for resistance to ear rot and leaf diseases in maize lines using biplots. Genet. Mol. Res. 14: 11052-11062. https://doi.org/10.4238/2015. September.21.18

Petatán-Sagahón I, Anducho-Reyes MA, Silva-Rojas HV, Arana-Cuenca A, et al. (2011). Isolation of bacteria with antifungal activity against the phytopathogenic fungi Stenocarpella maydis and Stenocarpella macrospora. Int. J. Mol. Sci. 12: 5522-5537. https://doi.org/10.3390/ijms12095522

R Core Team (2015). R: a language and environment for statistical computing. R Foundation for Statistical Computing. Available at [http://www.R-project.org/].

Reid LM, Zhu CX, Parker CA and Yan CW (2009). Increased resistance to Ustilago zeae and Fusarium verticillioides in maize inbred lines bred for Fusarium graminearum resistance. Euphytica 165: 567-578. https://doi.org/10.1007/ $\underline{\text { s10681-008-9782-6 }}$

Resende MDV and Duarte JB (2007). Precisão e controle de qualidade em experimentos de avaliação de cultivares. Pesq. Agropec. Trop. 37: 182-194.

Richter TE, Pryor TJ, Bennetzen JL and Hulbert SH (1995). New rust resistance specificities associated with recombination in the Rp1 complex in maize. Genetics 141: 373-381.

Robertson-Hoyt LA, Jines MP, Balint-Kurti PJ and Holland JB (2006). QTL mapping for fusarium ear rot and fumonisin contamination resistance in two maize populations. Crop Sci. 46: 1734-1743. https://doi.org/10.2135/ cropsci2005.12-0450

Rossouw JD, Van Rensburg JBJ and Van Deventer CS (2002). Breeding for resistance to ear rot of maize, caused by Stenocarpella maydis (Berk) Sutton. Evaluation of selection criteria. S. Afr. J. Plant Soil 19: 182-187. https://doi.org $\underline{10.1080 / 02571862.2002 .10634462}$

SAS Institute (2000). SAS/STAT User's Guide. Version 8. SAS Institute Inc., Cary.

Sibiya J, Tongoona P, Derera J, Van Rij N, et al. (2011). Combining ability analysis for Phaeosphaeria leaf spot resistance and grain yield in tropical advanced maize inbred lines. Field Crops Res. 120: 86-93. https://doi.org/10.1016/j. fcr.2010.09.001

Sidhu GS (1984). Parasitic epistasis. Phytopathology 74: 382-384. https://doi.org/10.1094/Phyto-74-382

Vivek BS, Odongo O, Njuguna J, Imanywoba J, et al. (2010). Diallel analysis of grain yield and resistance to seven diseases of 12 African maize (Zea mays L.) inbred lines. Euphytica 172: 329-340. https://doi.org/10.1007/s10681009-9993-5

Wanlayaporn K, Authrapun J, Vanavichit A and Tragoonrung S (2013). QTL Mapping for Partial Resistance to Southern Corn Rust Using RILs of Tropical Sweet Corn. Am. J. Plant Sci. 4: 878-889. https://doi.org/10.4236/ajps.2013.44108

Wisser RJ, Balint-Kurti PJ and Nelson RJ (2006). The genetic architecture of disease resistance in maize: a synthesis of published studies. Phytopathology (96): 120-129.

Genetics and Molecular Research 16 (3): gmr16039716 
Wolak ME (2012). nadiv: an R package to create relatedness matrices for estimating non-additive genetic variances in animal models. Methods Ecol. Evol. 3: 792-796. https://doi.org/10.1111/j.2041-210X.2012.00213.x

Yan W, Hunt LA, Sheng Q and Szlavnics Z (2009). Cultivar evaluation and mega-environment investigation based on the GGE biplot. Crop Sci. 40: 597-605. https://doi.org/10.2135/cropsci2000.403597x

Genetics and Molecular Research 16 (3): gmr16039716 